\title{
Multiorgan tropism of SARS-CoV-2 lineage B.1.1.7
}

\author{
Benjamin Ondruschka ${ }^{1}$. Fabian Heinrich ${ }^{1}$ - Maja Lindenmeyer ${ }^{2} \cdot$ Carolin Edler $^{1} \cdot$ Dustin Möbius $^{1} \cdot$ Jan Czogalla ${ }^{2}$. \\ Axel Heinemann ${ }^{1} \cdot$ Fabian Braun ${ }^{2} \cdot$ Martin Aepfelbacher $^{3} \cdot$ Marc Lütgehetmann $^{3} \cdot$ Tobias B. Huber $^{2}$
}

Received: 15 June 2021 / Accepted: 23 August 2021 / Published online: 6 September 2021

(c) The Author(s) 2021

\begin{abstract}
Due to the development of novel functionalities, distinct SARS-CoV-2 variants such as B.1.1.7 fuel the current pandemic. B.1.1.7 is not only more transmissible, but may also cause an increased mortality compared to previous SARS-CoV-2 variants. Human tissue analysis of the SARS-CoV-2 lineage B.1.1.7 is urgently needed, and we here present autopsy data from 7 consecutive SARS-CoV-2 B.1.1.7 cases. The initial RT-qPCR analyses from nasopharyngeal swabs taken post mortem included typing assays for B.1.1.7. We quantitated SARS-CoV-2 B.1.1.7 viral load in autopsy tissue of multiple organs. Highest levels of SARS-CoV-2 B.1.1.7 copies normalized to ß-globin were detected in the respiratory system (lung and pharynx), followed by the liver and heart. Importantly, SARS-CoV-2 lineage B.1.1.7 was found in $100 \%$ of cases in the lungs and in $85.7 \%$ in pharynx tissue. Detection also in the kidney and brain highlighting a pronounced organ tropism. Comparison of the given results to a former cohort of SARS-CoV-2 deaths during the first wave in spring 2020 showed resembling organ tropism. Our results indicate that also SARS-CoV-2 B.1.1.7 has a relevant organ tropism beyond the respiratory tract. We speculate that B.1.1.7 spike protein's affinity to human ACE2 facilitates transmission, organ tropism, and ultimately morbidity and mortality. Further studies and larger cohorts are obligatory to proof this link.
\end{abstract}

Keywords Autopsy $\cdot$ SARS-CoV-2 $\cdot$ Variants of concern $\cdot$ Organ tropism $\cdot$ B.1.1.7

Due to the development of novel functionalities, distinct SARS-CoV-2 variants such as B.1.1.7 fuel the current pandemic. SARS-CoV-2 lineage B.1.1.7 was first identified in the UK and spread in multiple regions worldwide [1]. B.1.1.7 is not only more transmissible, but may also cause an increased mortality compared to previous SARS-CoV-2

Benjamin Ondruschka and Fabian Heinrich are first authors and contributed equally to this work.

Marc Lütgehetmann and Tobias B. Huber are shared senior authors contributing equally to this work.

Benjamin Ondruschka

b.ondruschka@uke.de

Tobias B. Huber

t.huber@uke.de

1 Institute of Legal Medicine, University Medical Center Hamburg-Eppendorf, Hamburg, Germany

2 III. Department of Medicine, University Medical Center Hamburg-Eppendorf, Hamburg, Germany

3 Institute of Medical Microbiology, Virology and Hygiene, University Medical Center Hamburg-Eppendorf, Hamburg, Germany variants [2]. We have previously reported a multiorgan tropism of the initial SARS-CoV-2 lineage $[3,4]$ that can also associate with organ outcome [5]. Organ tropism thereby correlated with the presence of comorbidities including chronic kidney disease and diabetes [5]. The first case report on autopsy results of a B.1.1.7 fatality was published recently in Int J Legal Med [6].

Human tissue analysis of the SARS-CoV-2 lineage B.1.1.7 is urgently needed, and we here present autopsy data from 7 consecutive SARS-CoV-2 B.1.1.7 cases (clinical data in Table 1). These individuals died out-of-hospital $(n=3)$ and in-hospital $(n=4)$. The cohort was of high age (median 75 years, interquartile range 52-78 years) with a sex ratio of 4:3 (male:female). The initial RT-qPCR analyses from nasopharyngeal swabs taken post mortem included typing assays for B.1.1.7 in the form of N501Y and del HV69//70 as recently established [7] in combination with screening for E484K and P681H (TIB Molbiol, Berlin, Germany). All outof-hospital deceased were first tested positive post mortem. Full autopsies were done in all cases following guidelines on the handling of COVID-19 deaths [8]. Organ samples were processed and analyzed for the E gene of SARS-CoV-2. 
Table 1 Summary of case characteristics including sex, age, post-mortem interval (PMI), number of pre-existing medical conditions and places of death $(\mathrm{OH}$ out of hospital, $N W$ normal ward, $I C U$ intensive care unit). Forensic aspects of no. 1 have been published as case report [6]

\begin{tabular}{lllllllllll}
\hline No & Sex & Age & PMI & Place of death & $\begin{array}{l}\text { Comorbidi- } \\
\text { ties }(n)\end{array}$ & Airway $(n)$ & $\begin{array}{l}\text { Cardiovas- } \\
\text { cular }(n)\end{array}$ & Kidney $(n)$ & $\begin{array}{c}\text { Brain }(n) \\
\text { Metabo- }\end{array}$ & $\begin{array}{l}\text { Other }(n) \\
\text { lism }(n)\end{array}$ \\
\hline 1 & $\mathrm{f}$ & 70 & 6 & OH & 4 & 1 & 2 & 1 & 0 & 0 \\
2 & $\mathrm{~m}$ & 76 & 2 & NW & 4 & 0 & 3 & 0 & 0 & 0 \\
3 & $\mathrm{f}$ & 78 & 6 & OH & 4 & 1 & 2 & 0 & 0 & 1 \\
4 & $\mathrm{~m}$ & 85 & 4 & ICU & 4 & 0 & 3 & 0 & 0 & 0 \\
5 & $\mathrm{~m}$ & 45 & 2 & ICU & 2 & 0 & 1 & 0 & 0 & 0 \\
6 & $\mathrm{~m}$ & 75 & 12 & ICU & 5 & 1 & 2 & 1 & 0 & 1 \\
7 & $\mathrm{f}$ & 52 & 8 & OH & 3 & 0 & 2 & 0 & 0 & 0 \\
\hline
\end{tabular}

\section{SARS-CoV-2 viral load in key organs}

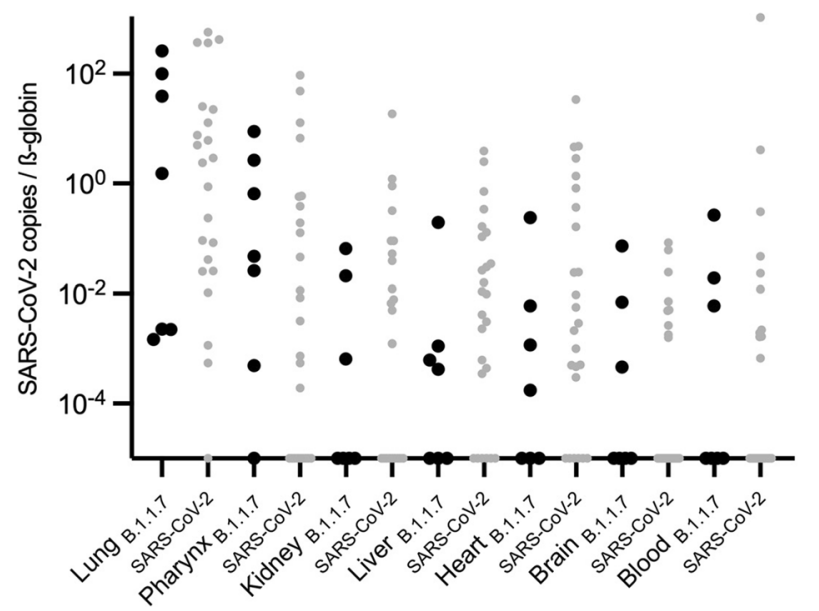

Fig. 1 Multi-organ tropism of the SARS-CoV-2 B.1.1.7 lineage. SARS-CoV-2 viral load in key organs, documenting organotropism of B.1.1.7 (virus copies normalized to B-globin). For comparative reasons, values from Puelles et al. [3] were opposed in grey dots as SARS-CoV-2 original lineage values and were also normalized to B-globin

We quantitated SARS-CoV-2 B.1.1.7 viral load in autopsy tissue of multiple organs. Highest levels of SARS-CoV-2 B.1.1.7 copies normalized to $B$-globin were detected in the respiratory system (lung and pharynx), followed by the liver and heart (Fig. 1). Importantly, SARS-CoV-2 lineage B.1.1.7 was found in $100 \%$ of cases in the lungs $(7 / 7)$, in $85.7 \%$ in pharynx tissue $(6 / 7)$, in $57.1 \%$ in the liver and heart $(4 / 7$ each), and in $42.9 \%$ in the kidney and brain (3/7) highlighting a pronounced organ tropism (Fig. 1). Comparison of the given results to a former cohort of 27 SARS-CoV-2 deaths during the first wave in spring 2020 [3] showed resembling organ tropism (Fig. 1).

Our results indicate that also SARS-CoV-2 B.1.1.7 has a relevant organ tropism beyond the respiratory tract. We speculate that B.1.1.7 spike protein's affinity to human ACE2 facilitates transmission, organ tropism, and ultimately morbidity and mortality. Further studies and larger cohorts are obligatory to proof this link and our forensic discipline is again one of the key players for this task.

Funding Open Access funding enabled and organized by Projekt DEAL. The authors were funded by the German Federal Ministry of Education and Research (BMBF: 01KX2021) as part of the DEFEAT PANDEMIcs project.

TBH was supported by the German Research Foundation (DFG: CRC/1192, HU 1016/8-2, HU 1016/11-1, HU 1016/12-1), the BMBF (STOP-FSGS-01GM1518C), and DEFEAT PANDEMIcs (01KX2021).

\section{Declarations}

Informed consent Informed consent was obtained from the relatives of the deceased. We want to offer condolences to the families and friends of all COVID-19 deceased.

Conflict of interest The authors declare no conflict of interest.

Open Access This article is licensed under a Creative Commons Attribution 4.0 International License, which permits use, sharing, adaptation, distribution and reproduction in any medium or format, as long as you give appropriate credit to the original author(s) and the source, provide a link to the Creative Commons licence, and indicate if changes were made. The images or other third party material in this article are included in the article's Creative Commons licence, unless indicated otherwise in a credit line to the material. If material is not included in the article's Creative Commons licence and your intended use is not permitted by statutory regulation or exceeds the permitted use, you will need to obtain permission directly from the copyright holder. To view a copy of this licence, visit http://creativecommons.org/licenses/by/4.0/.

\section{References}

1. Plante JA, Mitchll BM, Plante KS, Debbink K, Weaver SC, Menachery VD (2021) The variant gambit: COVID-19's next move. Cell Host Microbe 29:508-515

2. Davies NG, Jarvis CI, CMMID COVID-19 Working Group, Edmunds WJ, Jewell NP, Diaz-Ordaz K, Keogh RH (2021) Increased mortality in community-tested cases of SARS-CoV-2 lineage B.1.1.7. Nature 593:270-274 
3. Puelles VG, Lütgehetmann M, Lindenmeyer MT, Sperhake JT, Wong MN, Allweiss L, Chilla S, Heinemann A, Wanner N, Liu S, Braun F, Lu S, Pfefferle S, Schröder AS, Edler C, Gross O, Glatzel M, Wichmann D, Wiech T, Kluge S, Püschel K, Aepfelbacher M, Huber TB (2020) Multiorgan and renal tropism of SARS-CoV-2. N Engl J Med 383:590-592

4. Edler C, Schröder AS, Aepfelbacher M, Fitzek A, Heinemann A, Heinrich F, Klein A, Langenwalder F, Lütgehetmann M, Meißner K, Püschel K, Schäder J, Steurer S, Mushumba H, Sperhake JP (2020) Dying with SARS-CoV-2 infection - an autopsy study of the first consecutive 80 cases in Hamburg, Germany. Int J Legal Med 134:1275-1284

5. Braun F, Lütgehetmann M, Pfefferle S, Wong MN, Carsten A, Lindenmeyer MT, Nörz D, Heinrich F, Meißner K, Wichmann D, Kluge S, Gross O, Püschel K, Schröder AS, Edler C, Aepfelbacher M, Puelles VG, Huber TB (2020) SARS-CoV-2 renal tropism associates with acute kidney injury. Lancet 396:597-598

6. Heinrich F, Romich C, Zimmermann T, Kniep I, FItzek A, Steurer S, Glatzel M, Nöz D, Günther T, Czech-Sioli M, Fischer
N, Grundhoff A, Lütgehetmann M, Ondruschka B, (2021) Dying of VOC-202012/01 - multimodal investigations in a death case of the SARS-CoV-2 variant. Int J Legal Med. https://doi.org/10. 1007/s00414-021-02618-8

7. Nörz D, Grunwald M, Olearo F, Fischer N, Aepfelbacher M, Pfefferle S, Lütgehetmann M (2021) Evaluation of a fully automated high-throughput SARS-CoV-2 multiplex qPCR assay with buildin screening functionality to DelHV69/70- and N501Y variants such as B.1.1.7. J Clin Virol 141:104894

8. Hanley B, Lucas SB, Youd E, Swift B, Osborn M (2020) Autopsy in suspected COVID-19 cases. J Clin Pathol 73:239-242

Publisher's note Springer Nature remains neutral with regard to jurisdictional claims in published maps and institutional affiliations. 